\title{
The oncological treatment and cardiotoxicity problem - the role of biomarkers
}

\author{
Magdalena Dudek, Marta Kałużna-Oleksy, Jacek Migaj, Maciej Lesiak, \\ Ewa Straburzyńska-Migaj
}

$1^{\text {st }}$ Department of Cardiology, Poznan University of Medical Sciences, Poland

Correspondence:

Magdalena Dudek $1^{\text {st }}$ Department of Cardiology, Poznan University of Medical Sciences, Poland e-mail: magdalena.dudek@skpp.edu.pl

Received: 28.10.2020 Accepted: 02.12 .2020

DOI: 10.24292/01.OR.420021220 Copyright (๐) Medical Education. All rights reserved.

\section{ABSTRACT}

Cancer and cardiovascular diseases are a leading causes of morbidity and mortality in developed countries. Cardiological complications of oncological treatment are a significant problem that can be manifested in both permanent and transient cardiac dysfunction including myocardial damage, left ventricular dysfunction, and heart failure, hypertension, ischemia, as well as arrhythmias or QT prolongation, which can be life-threatening. Early detection of cardiotoxicity due to cancer treatment is crucial in the prevention of adverse cardiovascular outcomes in this group of patients. In this review we try to summarize the role of biomarkers in the detection of cardiotoxicity due to cancer treatment. Key words: cardiotoxicity, biomarkers, cardiooncology, ST2, troponin 


\section{INTRODUCTION}

Cancer and cardiovascular diseases are a leading causes of morbidity and mortality in developed countries. In the United States, these two diagnoses account for over $50 \%$ of the total number of deaths [1]. Cardiovascular diseases and cancer are one of the leading causes of mortality, also in Poland [2]. Early cancer detection, as well as the use of new treatment methods and the improvement of care, means that mortality in this group decreases, and the survival time of patients increases [2]. Anticancer therapies are associated with the risk of causing cardiovascular toxicity [3]. Long-term observation of cancer survivors show that the leading cause of death in this group are cardiovascular diseases [4]. Cardiological complications of oncological treatment are a significant problem that can be manifested in both permanent and transient cardiac dysfunction [5] including myocardial damage, left ventricular dysfunction (LVD), and heart failure (HF), hypertension, ischemia, as well as arrhythmias or QT prolongation, which can be life-threatening [6-8]. Disturbing cardiovascular symptoms may appear shortly after starting treatment, even on the same day or much later, even after several years [9]. Growing concerns about cardiotoxicity associated with the use of cancer therapy have led to the development of cardio-oncology. New methods are being sought to help predict adverse cardiovascular effects in cancer patients [8, 10].

\section{BIOMARKERS}

Early detection of cardiotoxicity due to cancer treatment is crucial in the prevention of adverse cardiovascular outcomes in this group of patients. Currently, available data suggest that cardiotoxicity, detected at an early stage, is potentially reversible [11, 12]. The most common strategies for assessing the risk of cardiotoxicity, as a complication of oncological treatment, are an echocardiographic assessment of left ventricle ejection fraction (LVEF) or less frequently multigated acquisition scan (MUGA scan). Identifying patients with subclinical cardiac dysfunction who are at risk of developing heart failure, by using cardiac biomarkers, may be crucial for matching the right therapy and minimize the development of cancer treatment-induced cardiotoxicity. What is more, cardiac biomarkers may be useful in this group of patients for adjusting personalized oncological treatment and rapid implementation of cardioprotection. In 2016 European Society of Cardiology (ESC) published a position paper regarding the management of the cardiotoxicity developed after oncological treatment [8]. A year later, the American Society of Clinical Oncology published similar guidelines [13]. According to that documents, cardiac biomarkers, such as troponin and natriuretic peptides, may be considered as an additive tool in diagnosing myocardial damage.
Troponin is one of the most established cardiac biomarkers for acute coronary syndrome and is routinely measured in acute myocardial infarction and has diagnostic and prognostic value [12]. Troponin is a sensitive and specific marker of myocardial injury and, apart from an acute coronary syndrome, may be elevated in case of heart failure, arrhythmia, pulmonary embolism and may be present in patients with cancer. The association of elevated troponin I (Tnl) levels in cancer patients with cardiotoxicity has been investigated in several studies. Newly elevated Tnl may identify patients form a group with poor prognosis [14]. The new elevation of high sensitivity troponin I can predict cardiotoxicity occurrence in patients treated with doxorubicin and/or trastuzumab [15]. Kitayama et al. obtained similar results that elevated levels of high sensitive troponin $\mathrm{T}$ in breast cancer patients can also predict the occurrence of cardiotoxicity [16].

Natriuretic peptides, $\mathrm{N}$-terminal pro brain natriuretic peptide (NT-proBNP) and brain natriuretic peptide (BNP), are secreted from the cardiac ventricles as a response to increased wall tension may be used as a biomarker [17]. NT-proBNP is a well-established biomarker for the diagnosis of heart failure and is associated with prognosis in HF patients. A recent study showed that NT-proBNP increases during trastuzumab treatment and is correlated with LVEF [18], which is consistent with previous findings [19]. Romano et al. showed that measurements of NT-proBNP might be useful for early detection of cardiotoxicity in patients receiving anthracyclines [18]. The cardiotoxicity related to anthracycline therapy also may be detected by using BNP [20].

Many other biomarkers are currently being studied and may have potential utility in the detection of early cardiotoxicity and outcome prediction. In a recent publication, Canada et al. showed that elevated levels of C-reactive protein (CRP) are common in a group of patients receiving chest radiotherapy [21]. They found a correlation between CRP levels and LVEF, which was lower in a group with elevated CRP. The results of this study suggest that changes in CRP levels may be useful for outcome prediction in patients receiving radiotherapy, however due to small sample size, further research in this field is needed.

Myeloperoxidase (MPO), an enzyme released by neutrophils, in periods of inflammatory stress and is considered as a biomarker of cardiotoxicity. Oxidative stress is thought to be one of the causes of cardiotoxicity caused by doxorubicin and trastuzumab. Ky et al. study suggest that MPO can be an adjunct biomarker to troponin [15]. Increased MPO levels are associated with cardiotoxicity over the entire course of doxorubicin and trastuzumab therapy [22]. These findings are encouraging for further studies in this field. 
Soluble ST2 (sST2) is a promising biomarker being investigated in many fields of cardiology [23]. ST2 participates in inflammatory processes and functions in relation to immune diseases. What is more, ST2 with interleukin-33, takes part in the cardioprotective pathway that prevents fibrosis and inhibits the inflammatory response, hypertrophy, and apoptosis of cardiomyocytes. SST2 as a novel biomarker seems to be especially important for monitoring acute and chronic HF [24, 25]. Considering the release mechanism of sST2 and its usefulness in the assessment of patients with heart failure, it appear that determination of sST2 may be useful in patients with cardiotoxicity after oncological treatment.

\section{SUMMARY}

Drug administration in the prevention of cardiotoxicity is the subject of ongoing research. ESC advise treatment with ACE inhibitor when an absolute LVEF decline of $>10 \%$ [8]. Adminis- tration cardiac medications for the prevention of cardiotoxicity in patients with normal cardiac function and low risk before oncological treatment needs more research to be done. However, there is promising meta-analysis endorsing preventive drug administration [26]. Treatment with dexrazoxane, $\beta$-blocker, statin or angiotensin antagonists may play a role in reducing cardiotoxicity [26]. A recent publication shows that ramipril treatment exerts potentially protective effects on cardiotoxicity [27].

The potential impact of cancer therapy on the cardiovascular system becomes a challenge for oncologists and cardiologists. The goal is to find a balance between oncological therapy, often life-saving, and the possibility of cardiotoxic side effects that reduce the quality of life and shorten its duration. Given the limitations of currently available biomarkers an approach based on the simultaneous assessment of multiple markers is recommended.

\section{References}

1. Murphy SL, Kochanek KD, Xu J et al. Mortality in the United States, 2014. NCHS Data Brief. 2015; 229: 1-8.

2. Jemal A, Ward E, Thun M. Declining Death Rates Reflect Progress against Cancer. PLoS One. 2010; 5(3): e9584. https://doi.org/10.1371/journal. pone.0009584.

3. Cautela J, Lalevee $\mathrm{N}, \mathrm{Ammar} \mathrm{C}$ et al. Management and research in cancer treatment-related cardiovascular toxicity: Challenges and perspectives. Int J Cardiol. 2016; 224: 366-75. https://doi.org/10.1016/j.ijcard.2016.09.046.

4. Rugbjerg K, Mellemkjaer L, Boice JD et al. Cardiovascular disease in survivors of adolescent and young adult cancer: a Danish cohort study, 1943-2009. J Nat Cancer Inst. 2014; 106(6): dju110. https://doi.org/10.1093/jnci/dju110.

5. Suter TM, Ewer MS. Cancer drugs and the heart: importance and management. Eur Heart J. 2013; 34(15): 1102-11. https://doi.org/10.1093/eurheartj/ehs181.

6. Dudek M, Lesiak M, Straburzyńska-Migaj E et al. Powikłania sercowo-naczyniowe u pacjentów z chorobą nowotworową otrzymujących chemioterapię lub radioterapię. WDR. 2019; 50(1): 8-13. https://doi.org/10.5604/01.3001.0013.1683.

7. Zamorano JL, Lancellotti P, Rodriguez Muñoz D et al. 2016 ESC Position Paper on cancer treatments and cardiovascular toxicity developed under the auspices of the ESC Committee for Practice Guidelines. Eur J Heart Fail. 2017; 19(1): 9-42. https://doi.org/10.1002/ejhf.654.

8. Aleman BMP, Moser EC, Nuver J et al. Cardiovascular disease after cancer therapy. EJC Suppl. 2014; 12(1): 18-28. https://doi.org/10.1016/j.ejcsup.2014.03.002.

9. Chen MH, Colan SD, Diller L et al. Cardiovascular disease: cause of morbidity and mortality in adult survivors of childhood cancers. Circ Res. 2011; 108(5): 619-28. https://doi.org/10.1161/CIRCRESAHA.110.224519.

10. Plana JC, Galderisi M, Barac A et al. Expert consensus for multimodality imaging evaluation of adult patients during and after cancer therapy: a report from the American Society of Echocardiography and the European Association of Cardiovascular Imaging. J Am Soc Echocardiogr. 2014; 27(9): 911-39. https://doi.org/10.1016/j.echo.2014.07.012.

11. Ewer MS, Suter TM, Lenihan DL et al. Cardiovascular events among 1090 cancer patients treated with sunitinib, interferon, or placebo: a comprehensive adjudicated database analysis demonstrating clinically meaningful reversibility of cardiac events. Eur J Cancer. 2014; 50(12): $2162-70$. https://doi.org/10.1016/j.ejca.2014.05.013.

12. Armenian SH, Lacchetti C, Barac A et al. Prevention and Monitoring of Cardiac Dysfunction in Survivors of Adult Cancers: American Society of Clinical Oncology Clinical Practice Guideline. J Clin Oncol. 2017; 35(8): 893-911. https://doi.org/10.1200/JCO.2016.70.5400.

13. Roffi M, Patrono C, Collet JP et al. 2015 ESC Guidelines for the management of acute coronary syndromes in patients presenting without persistent ST-segment elevation: Task Force for the Management of Acute Coronary Syndromes in Patients Presenting without Persistent ST-Segment Elevation of the European Society of Cardiology (ESC). Eur Heart J. 2016; 37(3): 267-315. https://doi.org/10.1093/eurheartj/ehv320.

14. Cardinale D, Sandri MT, Martinoni A et al. Left ventricular dysfunction predicted by early troponin I release after high-dose chemotherapy. J Am Coll Cardiol. 2000; 36(2): 517-22. https://doi.org/10.1016/s0735-1097(00)00748-8.

15. Ky B, Putt M, Sawaya H et al. Early Increases in Multiple Biomarkers Predict Subsequent Cardiotoxicity in Patients With Breast Cancer Treated With Doxorubicin, Taxanes, and Trastuzumab. J Am Coll Cardiol. 2014; 63(8): 809-16. https://doi.org/10.1016/j.jacc.2013.10.061.

16. Kitayama $\mathrm{H}$, Kondo $\mathrm{T}$, Sugiyama $\mathrm{J}$ et al. High-sensitive troponin $\mathrm{T}$ assay can predict anthracycline- and trastuzumab-induced cardiotoxicity in breast cancer patients. Breast Cancer. 2017; 24(6): 774-82. https://doi.org/10.1007/s12282-017-0778-8.

17. McCullough PA. B-type natriuretic peptides. A diagnostic breakthrough in heart failure. Minerva Cardioangiol. 2003; 51(2): 121-9.

18. Bouwer NI, Liesting C, Kofflardet MJM et al. NT-proBNP correlates with LVEF decline in HER2-positive breast cancer patients treated with trastuzumab. Cardiooncology. 2019; 5(1). https://doi.org/10.1186/s40959-019-0039-4.

19. Romano S, Fratini S, Ricevuto E et al. Serial measurements of NT-proBNP are predictive of not-high-dose anthracycline cardiotoxicity in breast cancer patients. Br J Cancer. 2011; 105(11): 1663-8. https://doi.org/10.1038/bjc.2011.439. 
20. Lenihan DJ, Stevens PL, Massey M et al. The Utility of Point-of-Care Biomarkers to Detect Cardiotoxicity During Anthracycline Chemotherapy: A Feasibility Study. J Card Fail. 2016; 22(6): 433-8. https://doi.org/10.1016/j.cardfail.2016.04.003.

21. Canada JM, Thomas GK, Trankle CR et al. Increased C-reactive protein is associated with the severity of thoracic radiotherapy-induced cardiomyopathy. Cardiooncology. 2020; 6: 2. https://doi.org/10.1186/s40959-020-0058-1.

22. Putt M, Hahn VS, Januzzi JL et al. Longitudinal Changes in Multiple Biomarkers Are Associated with Cardiotoxicity in Breast Cancer Patients Treated with Doxorubicin, Taxanes, and Trastuzumab. Clin Chem. 2015; 61(9): 1164-72. https://doi.org/10.1373/clinchem.2015.241232.

23. Dudek M, Kałużna-Oleksy M, Migaj J et al. Clinical value of soluble ST2 in cardiology. Adv Clin Exp Med. 2020; 29(10): 1205-10. https://doi. org/10.17219/acem/126049.

24. Aimo A, Vergaro G, Passino C et al. Prognostic Value of Soluble Suppression of Tumorigenicity-2 in Chronic Heart Failure: A Meta-Analysis. JACC Heart Fail. 2017; 5(4): 280-6. https://doi.org/10.1016/j.jchf.2016.09.010.

25. Emdin M, Aimo A, Vergaro G et al. sST2 Predicts Outcome in Chronic Heart Failure Beyond NT-proBNP and High-Sensitivity Troponin T. J Am Coll Cardiol. 2018; 72(19): 2309-20. https://doi.org 10.1016/j.jacc.2018.08.2165.

26. Kalam K, Marwick TH. Role of cardioprotective therapy for prevention of cardiotoxicity with chemotherapy: a systematic review and meta-analysis. Eur J Cancer. 2013; 49(13): 2900-9. https://doi.org/10.1016/j.ejca.2013.04.030.

27. Słowik A, Jagielski P, Potocki $P$ et al. Anthracycline-induced cardiotoxicity prevention with angiotensin-converting enzyme inhibitor ramipril in women with low-risk breast cancer: results of a prospective randomized study. Kardiol Pol. 2020; 78(2): 131-7. https://doi.org/10.33963/KP.15163.

Authors' contributions:

Magdalena Dudek: idea of the manuscript, collecting the data, writing the manuscript: Marta Kałużna-Oleksy: idea of the manuscript, writing the manuscript; Jacek Migaj: collecting the data; Maciej Lesiak: collecting the data, review; Ewa Straburzyńska-Migaj: idea of the manuscript, review.

Conflict of interests: Authors declare no conflict of interest.

Financial support:

There was no financial support.

Ethics:

The authors had full access to the data and take full responsibility for its integrity.

All authors have read and agreed with the content of the manuscript as written. The paper complies with the Helsinki Declaration, EU Directives and harmonized requirements for biomedical journals. 